\title{
Cezayı azaltıci takdiri sebebler
}

\author{
Doçent' Di. Faruk EREM
}

$\$ 1$ TAKDIRI SEBEBLERIN GAYEST: (1) Vazu kanư tarafindan suçlu tanmmaksızin 'tesbit edilmiş olan cezanm, suçluya uydurulması, diğer bir deyimle, suç ve suçlunun bütün hususiyetleri göz önünde tutarak verilmesi gereken en uygưn cezayl tâyini, kısaca, "Cezanm ferdileştirilmesi» faaliyeti ancak. "Cezay Azalțcı Takdiri Sebeb" müessesesi ile kabildir.

Her suçun cezasının kanunda bir aşağı ve bir de yukarı had arasında tayin edilmiş olmasına ve bu ikj had arasinda yargıcın «Umumî Takdir Hakk1) n1 kullanarak suçluya verilecek temel cezayı tayin edebileceğine bakarak ayrıca cezayı azaltıcı takdiri sebeb müessesesine ihtiyaç olmadığı neticesine varmak doğru değildir. Evvelâ kanunda usabit ceza)lı yani cezası aşağı ve yukarı had arașnda gösterilmemiş (ölüm cezasmu, müebbed ağur hapis cezasın1, nisbi para cezasinı müstelzim) suçların mecvut olduğu unutulmamalıdır. Diğẹ taraftan suçların işlenme şekli, işleyenin sosyal ve psikolojị durumu namütenahi bir değişiklik arzeder. Bu sebeble hiß̧bir suçlu diğerine, hiçbir sụç başka bir suça benzer, denilemez. Hadisenin bütün hususiyetleri göz önünde tutularak verilecek cezanin ve ancak böyle bir cezanın sosyal ve psikoloojik bir değer taşıyabileceği va bu namütenahi hususiyetlerin kanunlarda evvelden tayinine imkân olmadığı düşünülecek olursa cezayn azalticı takdiri sebeplere: olan ihtiyą̧ daha fazla kendini gösterir.

Tukdine bağh cezayı azaltıcı sebeblerin faidesi umumiyetle kabul edilmekle beraber, bu müessesenin mahzurlamnin da meveut olduğu ileri sürülmektedir. Ezcümle bú müesseseye «kısa müddetli ce-

(1) Bibliyografya: BRUNO, Codice penale del rengno d'italia. -DONNEDEEU DE VABRRS, Traitó élémontaire de droit criminel et de legislation pénate comparé, basi 2, Paris 1943. GARRAUD, Traité théorique et pratique du droit pénal français, C II basi3, Paris 1914. - MAJNO, Commento al codice pónple italiano; C. I, bas1 4, Torino 1924. -MANZINI, trattato di diritto pénale italiano. C. II, basi 2, Tarino 1926. -RQUX, Cours de droit crimind français, bas1 2, S. I, Paris 1927. -VIDAL, Cours de droit criminel et de science pénitentaire, basi 8, Paris 1935.

Hulkuk Fakültesi Mermuas1: 9 
zalar" suiistimalinin başhıca kaynağı gözü ile bakmak mümkündür. Fakat zannımıza göre bu itiraz müessesenin esasına değil, takdir hakkının yerinde ve makul ölçülerle kullanılmamasına taallûk eder (2).

Kanunumuż "Cezayi Azaltıcı Takdiri Sebebler» müessesesini sarahaten kabul etmiştir (TCK m. 59). Fakat "Cezayı Arttırıcı Takdiri Sebeb" mefhumu kanunumuza yabancidır. Esasen cezanin ne sekilde olursa olsun arttırilabilmesi, ancak "Kanunî̀" sebeblerle olmalıdır. Aksi takdirde "kanunsuz ceza olmaz" kaidesine muhalefet edilmiş olur. Halbuki takdiri sebeblerle, kanunun verdiği cezayı hafifletmekte bu kaideye aykırı bir cihet yoktur.

§ 2 TAKDIRI SEBEBLERIN TAYINI: Türk Ceza Kanunu, mahkemece takdiri sebeblerin kabulü halinde cezanın nasil indirileceğini bildirmekle beraber, nelerin veya ne gibi hallerin takdiri sebeb sayllacağın tasrih etmemektedir. Doktrinde ise bu sahada tam bir ölçü teklifinden kaçınılmaktadır. Çünkü her türlü ölçü, kayıtsız ve şartsiz olmadıcça bir mana ifade edemiyecek olan "takdir" mefhumuna aykırı düşer. Adli işlerde, murakabeye tabi takdir hakkınm mevcut olabileceğini sanmıyoruz. Bu sebeble, herhangi bir hâdisede Cezayı Azaltıcı Takdirî sebeblerin mevcut olup olmadığının tayini davayı gören yargıca aittir. Şu veya bu vakianın Cezayı Azaltıcı takdiri sebeb sayllp saylmıyacağı hususunda da hükmü veren mahkemeden daha yüksek bir mahkemenin bozma hakkı olmamalıdır.

Mutlak mânada anlaş̧lması zarurî olan "Taktir Hakkımnı ancak kanunî tahdidlerine yer verilebilir. Bu sebeble Cezayı Azaltıcı Takdiri Sebebler sahasında, muayyen vakaların böyle bir sebeb saylmas1 veya sayılmaması yolunda takarrür etmiş bir içtihada riayet mecburiyeti, zannımıza göre, doğru değildir. (3)

Duvayı gören mahkemenin kabul ettiği veya etmediği sebeb üzerinde yargitayın murakabesi hususunda yargıtayımızın kat'ì kanaatini gösteren yerleşmiş bir içtihada rastlanmamaktadır. Takdiri Azaltıcı Sebeblerin mevcut olup olmadığının ve bir vakıanın böyle bir sebeb kabul edilmesi veya edilmemesi husunsunun davayı gören - mahkemeye ait olduğunu kabul eden yargıtay kararlarına (4) rast-

(2) Cezayı Azaltıc Takdiri Sebeb mefhumu hakkında bk. Garraud, n. 834; Manzini n. 373; Vidal n. 239; Majno, n. 273; Donnedieu de vabres n. 779.

(3) Aksi kanaat, CGK 10. 1. 1944 e, 16 k. tem. kar. 944, s. 24: «Devlete ait hissenin mühim bir miktarının ödenmiş olması hususunun cezanın hafifletilmesini icap edeceği temyizin müstakar içtihadı cümlesindendir».

(4) I CD 30.12 .943 e. 2515 k. 3120 tem. kar. 944 s. 31: *Takdire bağlı 
lanmakla beraber, bunun aksini gösteren kararlara (5) dà tesadüf edilmektedir. Yargitayın bozma kararlarında sik stk rastlanan bozma sebebi, hükmü veren mahkemenin «Tezadı takdireve düşmüş olmasıdır, Yargıtayımızın Takdirde Tezat saydığı husưsların, hakikaten tezat sayılmasina imkân görmemekteyiz, Çünkủ cezanin tayini ameliyesi, netice verinceye kadar, cezaların artturilması, eksiltilmesi faaliyetine ihtiyaç gösterir. Bír külden ibaret olan bu ameliyenin muhtelif săfhalarında, yargıç takdirini daima aynı şekilde kullanmak mecburiyetinde değildir. Meselâ yargitay takdiri aźaltıcı sebeb kabul edilen bir hadisede mahkemenin, o suç hakkında kanunun tayin ettiğ cézanın aşağı haddinden üstün bir cezayı temel ceza kabul etmesini ve arttirma eksiltmelerin bu ceza üzerinden yapilmasinı aTezadi Tekdiri saymaktadı. Halbuki o suc hakkında kanunun kabul ettiği cezanụ aşağı ve yukarı hadlerinde, temel cezayı yani cezanı̣ hesaplanmasi ameliyesinde hareket mebdei saylacak cezayı tayinde yargıç. "Takdiri Azaltıcı Sebeb" mefhumundan ayr bir yetkiden faydalanır. $\mathrm{Bu}$ yetkisini yargıcın, suçlurtun aleyhinde kullanmak ihtiyacını duyması mümkündür. Kanunumuz cezayı arttırıcı "takdiri» sebeb müessesesini kabul etmediğine göre yargıcın, cezanın şiddet:lendirilmesi lüzumunu hissettiği zaman kullanacağı tek yetki aşağ ve yukarı had arasında cezayı takdir ederken suçlunun aleyhinde hareket etmesi imkânıdır. Aynı hâdisede yargıcı, takdiri azaltı̣̣ sebeb kabulüne, sevkedecek vakıalarla birlikte cezanın müessirir bị ceza olmasını gerektirecek sebepler de bulunabilir. Vakaların mahiyetirden ileri gelen bu tezad, «takdirde tezat" saylmamalidir. (6) (7).

hafiflotici sebebletin meveut olup olmadion talodiri mahkemeyre aittirs. Aynt mahiyette CGK 5,1.1942 tem. kar. 941-942 s. 107. CGK temi kar. 941-942 s. 203: cKaçalk kerestelerin ihbar edilmeksixin mektep inşastnda kullanilonasunin takdiri hafifletici sebeb addedilip edilmemesi mahkemeye aittr".

(5) 2 CD 13.11 .1937 e. 12785 k. 14080 tem kar 937 s. 333: : rKavganin esbabi gayri malumeden çikmış olmasının esbabi muhaffefei takdiriyeden olarak kabul editmesi veçhinin izah edilmemesi yolsuzdur» . -1 CD 15.5.941 tem kar. 941-942 s. 260: Aralarinda resmt rabitaya müstenit evlilik birlǐ̌̉i bülunmasa dahi yedi senedenberi beraber yasgadıgi ve bu münasebetten üc de

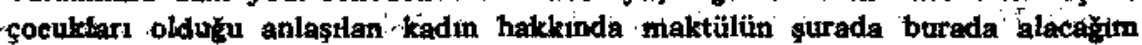
tiye söylentis olmatının suçluda husule getirdiği tabiî olan tesirle fiilín ika edilmesinde cezayı azalticr halin kabuliu ieap ederken yazllı şekilde hiọbir tahfif sebebi olmadišma torar veritmesi yolsuidurn:

(6) Tezad- takdir hakkindalk yargitay kärazlarma misal oimak üzere şu kararlar gösterilebilir: 1. CD 6.7. 936 e.. 2401 k. 1082, tem. kar. 936 s. 255: «Aynı şahıs hakkında aynı suçtan dolayı takłtiri azaltıc sebeb kabul edíl- 
Bir hâdisede cezayı azalticı takdiri sebebin kabulü, takdire dayanam büttün hükümlerin suçhumun lehinde netice verecek tarzda tatbiki mecburiyetini tevlit edemez. Bu sebeble İtalyan Yargitayı, Cezayı Azaltıcı Takdiri Sebeb kabul ettiği halde suçlunun tecil talebini reddeden hükmü mütenakız saymamıştır (8).

Bazı yargitay kararlarinda, Cezayı Azaltıcı Takdiri Sebeblerin "Sebebi makule" dayanması lâzım geldiği beyan edilmekte (9) ve "makul" saylmayan sebeblerin, takdiri sebeb olarak kabul edilemiyeceği bildirilmekttedir. Böyle bir içtihad, yargıçların takdir hakları için ciddî bir tehlike teşkil eder. Neyin makul neyin gayii makul olduğu yolunda bir münakaşa açılması "takdir hakkı" nm ortadan kalkmasina müncer olứr. Yalnız dosyanin tetkiki ile gayri makul gözüken bir sebebin, davanm bütün safhaları önünde cereyan etmiş olan bir yargica, bilâkis, çok yerinde ve makul gözükmesi mümkündür (10).

Mahkemece, Takdiri Sebebe mesnet saylan vakıanın hükümde göstenilmesi lüzưmu yargitay içtihadındandır( 11). bk. CMUK, m. 260 .

\$ 3, TAKDIR HAKKININ TAHDITLERI: Nelerin veya ne gibi hallerin Cezayı Azaltıcı takdiri Sebeb sayılacağı hususu kanunda gösterilmemiştir. Bunları tahdid etmeğe imkân yoktur. Şu hallerin, Takdiri Azaltıci Sebeb olarak kabul edilebileceği misal olarak gösterilebilir: Kendisinin veya başkasmin şerefini kurtarmak sạiki;

diği halde yine takdiren cezanın arttırılmast yolsuzdur», -1 CD 6.1.936 e. 534 k. 665 tem. kar. 936 s. 121 â *B. nin öldürülmesi suçunda Cezayı azaltıcı Sebebin bulunduogu kabul ve takdir edildiłgi halde yaşdan dolayı ceza tenzilinde fiilin mabiyeti takdiren cézayi arttumaga esas tutulmak ve birbirine uymayan bu takdirlerin ne suretle telif olunduro kararda gösterilmemiş olması yolsuzdury.

(7) Bu mesele hakkinda bk. Manzini n. 375

(8) Bruno m. 59

(9) I CD 6.8 .927 k. 385 , Köseoğlu. TCK m. 59

(10) Misal olmak üzere şu karas zihredilebilir, 1 CD $5.5 .928, \mathrm{k}, 1459$, Köseoğlu TCK m. 59, aynı karar Bora. TCK m. 59: «Esbabı muhaffefei takdiriyenin bir zabıtayı umumiye ve kaideyi hukukiye ile ifadesine imkânsızlık mevcut olmakla beraber her halde failin lekine esbabt makbule vemakuleden olması lâzım gelip failin nedameti vicdaniyesinden olmayarak mìcerred hakikatin tezahürüinü teshile notuf ikrarinan sebebi tahfif addi yolsuzdur».

(11) CGK 30.3.931 k. 32; Köseoglu TCK m. 59: "Takdiri Tahfif Sebebinin büxüm fıkrasında tafsil ve izah edilmesi lâzımđı̊n. 
Cemiyetin ve Ahlâk Telakkilerinin kötü saymadı̆ł̆l heyecanlar ve ihtirasłar; geçim zorlukları; lekesiz bir mazi; suçdan hiçhir zarar husule gelmemiş olması veya hușule gelẹ zarañ cüzî̀ oluşu, suelunuri yakalanmadan evvel samimî bir nedamet duyduğunu gösteren vakıalar; Kendi kendini ihbar; samimî ve tam bir itiraf; resmî makama kendiliğinden gelip teslim olmak veya kaçmak imkânı varken kaçmaniş olmak; hâdiseye sebebiyet vermeden mağdurun da kusurlu olmasi; ceza davasinm sưkûtu sebeblerinden birine çok yalkm olmak (dava zaman aşıminin dolmasından bir gün evvel yakaIanmak gibi); suçlunun cemiyet için büyük hizmet gờrmüş bir kimse olmasi (12).

Hèr hangi bir vakıayı yargıç Cezayi Azal tici Takdiri Sebeb olarak kabul edèbilir. Fakat bu hususta kanunî bazl tahditlerin mevcut olduğu aşikârdìr. Ezcümle kanunun, müstakil bir sebeb veya unsur olarak derpiş ettiği bir vakiayı, yargiç Takdiri Sebeb telakki edemez (13) Cezayı Azaltıcı Kanunî bir sebebin aynı zamanda Takdiri Azaltıcı sebeb sayılması da doğru değildir (14). Bu sebeble yukarıda misal olarak gösteriIen vakualarm Takdiri Sebeb Saylmasi, onlarm kanunî sebeb sayllmadı̆̆ hallerde mümkündür.

Bu sebeble; "Haksız Tahrik» in mevcut olduğu bir hâdiṣede 51 inci madde (15), "Hakaret" meselelerinde 485 inci madde (16, hadiseye mağdur memurun "Keyfi Hareket" lerinin sebebiyet vermiş olması halinde 272 inci madde (17), yerine 59 uncu maddenin tatbiki dogru değildir.

8 4. TAKDIRE BAGEI SEBEBLERLE CEZALARIN INDIRILLMESI: Cezayi Azaltici takdiri sebeblerin" mevcudiyeti halinde, cezanin 59 uneu màdede gösterilen nisbetler dahỉinde indirilmiesi lâzım gelizr: Bu indirme ameliyesi, Cezayı Azaltici Takdiri Sebeb meveut

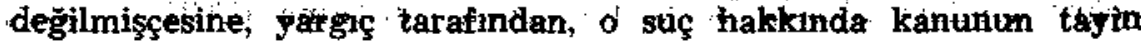
ettiğ aşaği ve yukari had arasindan seçecegi d Teithel Cezai üzerinden yapllı. Eğer Cezayı Azaltıcı Takdiri Sebeblerle birlikte diger. sebeblerde mevcut ișe evvelâ :Temel Cezain nin tayini, bundan son-

(12) bk. Manzini n. 374; Majno n. 274; İsviçre Ceza Kanunu m. 64

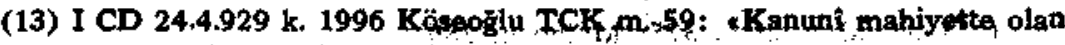
muhaffef sebeb, takdici sobeb addedilemezn.

(14) bk 4 CD 9. 9. 933 k 6810 Köseodu TCK m. 59

(15) 4 CD 26,4945 e, 4625 k. 4647 , Ad ders 945, s. 112 -I CD $27,12$. 941 tem, ka 941-942, I CD 13.5937, 3929, 1958 tem kar. 937 \$ 228

(16) 2 CD $24,6.941$ tem. kar. $941-942$ s. 362

(17) $4 \mathrm{CD} 17.2 .936$ e. 7413 k. 1293 tem. kar. 936 s. 397 
ra, 29 uncu maddede gösterildiği veçhile, cezanın arttırılması ve bunu takiben de cezanın indirilmesi ve fakat suçlunun yaşı, akli hali, Cezayı Azaltıci Takdiri Sebeb ve Tekerrür hususlarınin, bu sira takip olunmak üzere, en sonra nazara alınması lâzımdır.

Cezayı Azaltici Sebebin mevcut sayılması için, bu sebebden dolayı yapılacak indirme sonunda cezanin, o suç hakkmda kanunun kabul ettiği asgari hadden aşağıya düşmüş olması şart değildir. Yargı̧, aşağı, yukarı had arasında "Temel Ceza»yı seçtikten sonra 29 uncu maddedeki hükümler dairesinde cezayı arttırma-indoirme ameliyesini yapacak ve yine bu maddede gösterilen sirası gelince Takdiri Sebebden dolayı cezayı indirecektir. Bu ameliye sonunda elde edilecek ceza, kanunun o suç hakkmnda kabul ettiği asgari hadden yukarı olabileceği gibi, aşağ̀ya da düşmüş olabilir (18).

Kanun, Takdire Bağl Sebeblerin kabulü halinde . "cezalar" in indirileceğini beyan ediyor. Kanunun ( $m$. 59) ibaresi mụtlaktır. $O$ halde bir sự̧ hakkında kanunun tayin ettiği cezalardan yalnız birinin değil, hepsinin indirilmesi ve fakat bu indirmenin ceza sayılmıyacak olan hususlara da teşmil edilmemesi lâzımdır. Bu sebeple: a) Cezayı Azaltıcı Takdiri Sebeb'in kabulü halinde, o suç hakkında kanunun birlikte kabul ettiği müteaddit cezalardan birinin indirilip, diğerlerinin indirilmemesi doğmu değildir. $O$ halde kanun bir suç hakkında hem "Hürriyeti Bağlayıcı Ceza" ve hem de "Para Cezası" veya "Hukuku Bağlayıcı" bir ceza kabul etmiş ise, Takdiri Sebeb'in mevcudiyeti halinde, yalnız hürriyeti bağlayıcı cezanın indirilerek diğer cezaların indirilmemesi kanuna uygun sayılamaz (19). Yargstay da böyle içtihad etmiştir (20). b) Cezayı Azaltıc1. Takdiri Sebeblerin kabulü halinde ancak "Cezalar" indirilir. Ceza saylamiyacak hususların Takdiri Sebeblerle indirilmesî doğru değildir. Meselâ . Boğaz tokluğuna çalıştırma (TCK m. 554) ceza değil emniyet tedbiridir. Takdiri Sebeblerle bu tedbirin müddetinden indirme yapllamaz.

59 uncu maddenin Takdirí Sebeblerle münhasıran "Cezalar» dan indirme yapılacağını kabul etmiş olmasını göz önünde tutarak,.

(18) bk. Manzini n. 375; Majno n. 286

(19) Manzini n. 375; Majno n. 275; Italyan Yargitay karari, Bruno m. 59: Takdiri Takfif Sebebi kabul edilince bununla yalnız şahsî hürriyeti bağlayıcı ceza değłil amme hizmetlerinden memnuiyet cezası da indirilir».

(20) I CD 16.10 .936 e. 1194 k. 1603 tem. lar. 936 s. 243: "Takdiri Tahfif Sebєblerinin hükmedilen para ve memuriyetten mahrumiyet cezalarına da. tatbiki lâzimdır». 
o' suç hakkında kanumun kabul ettiği bütün cezalardan, yani asli cezalardan olduğu kadar, fer' $\mathbf{i}$ cezadan da indirme yaplmasi lâzum geldiği ve fakat bu indimmenin emniyet tetbirlerine -ibunlar ceza olmadıkları için teş̧mil edilemiyeceği neticesine varmıştık. Fakat bu netice Yargıtay içtihadına tamamiyle uygun saylamaz. Yüksek Mahkemeye göre: “Kanunî Sebebler haricinde fail lehine Cezayı Azaltıci Takdiri Sebeblerin meveudiyeti halinde kanụ vazil 59 uncu madde ile hakime Ceza Kanununda yazll bilumum cezalari ya tepdil veya bir kasmin! muayyen nisbet dahilinde tenzil hak ve salâhiyetini tanum ł olmasma: göre hâdisede Ceza Kanunụun 191 inci maddesinin ikinci fikrast ile tayin edilen fer'i ceza üzerinden de tenzilât yapilabilmesi 59 uncu maddenin sarih hükmüi muktazasmian iken 59 uncu madde hükmünün Ceza Kanunun 11 inci maddesinde yazilı cezalara hasrn suretiyle mutlak olan bir salâhiyetin kabul edilmemesi yolsuzudurm. Doğru sayamıacağımız bu içtihad, "Fer'i Ceza) mefhumu ile "Emniyet Tedbiri» mefhumunun tefrik edilmemesinden ileri gelmiştir. Şüphesiz 59 uncu madde yalnuz asli cezalara değil fer'i cezalara da tatbik edilecektir. Fakat 191 inci maddenin ikinci fikrasında bahis mevzuu olan «Emniyeti Umumiye Nezaretin: fer'i bir ceza değil, sadece Emniyet tetbiridir. Diğer taraftan Yargitay'n «Emniyeti Umumiye-Nezaretin ni "tedbir kabilinden". sayan içtihadi ile fer'i ceza sayan buradaki içtihadı arasinda tenakuz meveuttur.

A. ölüm cezası: Cezayı Azalticı Takdiri Sebebin kabulï halinde ölüm cezası yerine otuz sene Ağrr Hapis cezası verilir. Takdiri Sebebplerle ölüm ceasının ağır hapse tahvili halinde emniyeti umumiye nezareti de tatbik olunur (TCK m. 32).

B. MÜEBBED AĞR THAPIS: Cezayı Azaltıcı Sebellerin kabulü halinde Müebbet Ağır Hapis yerine yirmi dört sene Ağır Hapis hükmolunur Eğger kanunda yazılı Cezayı Azaltıcı hususî bir sebeb ile takdirî Sebeb içtima ederse, müebbed cezanm hususî sebebe ait olan kanun hükmü dairesinde evvelâ muvakkat bir cezaya çevrilmesi ve bundan sonra da cezanm altzda birinden üçte birine kadarmin indirilmesi lầzımdır.

C. DIĞER CEZALAR: Cezayı Azaltıcı Takdiri Sebeblerin kabulü halinde, ölüm ve müebbet Aggr Hapis cezalarından gayri cezaların altıda birinden üçte birine kadarı indirilir.

Meyhaz Kanun (diğer cezalar)!n altrda birinìn indirileceğini beyan etmektedir. Kanunumuz böylé sabit bir ölçü kabul etmemek ve cezanın altıda birinden ựte birine kadarmın indirilecegini kabul 
etmek suretiyle Takdiri Sebeblerin, hadiselerin hususiyetlerine daha kolaylhkla uydurabilmesini temin etmiştir. Bu sebeble Meyhaz kanunundan Kanunumuzun ayrilmuş olmasi yerindedir. Esasen Meyhaz Kanununun sabit bir tenzilât nisbeti kabul etmiş olması, İtalyan müellifleri tarafından tenkit edilmiştir (21).

Müebbeden Amme hizmetlerinden mahrumiyet cezasinın Takdirî Sebeblerle azaltilmasına imkân yoktur. Her ne kadar 59 uncu maddede kullanılan "diğer cezalar" tabirlerine "amme hizmetlerinden müebbet memuiyet" cezası dahil ölabilirse'de, müddeti olmayan bu cezanın altıda birinden üçte birine kadarının indirilmesi mümkün değildir. Kanunun, ölüm cezası hakkında bile, Takdîrî Sebeblerle indirme yapllmasin kabul etmesine mukabil, amme hizmetlerinden müebbet memnuiyet cezasından indirme yapliması imkânını vermemiş olmasının sebebi anlaşılmamaktadır. (22).

59 uncu maddedeki "diğer cezalar" tabirine "nisbî para cezaları" dahildir. Cezayı Azaltıcı Takdirî Sebeb mevcut ise yargıç nisbî para cezalarınm da altıda birinden üçte birine kadarmı indirir. Yargitay (nisbî para cezalamndan takdire bağlı hafifletici sebeblerle, bu cezaların hapse çevrilmesinde nazara alınmak şartı ile, tenzilât yapilması lâzum geleceğin fikrindedir (23). Takdirî Sebeblerle nisbî para cezalarnım, ancak hapse çevrilmesi bahis mevzuu olunca azaltılması ve diğer hallerde azaltılmaması sebebini izah etmek, zannımıza göre, imkânsızdır. Nisbî para cezaları yainız aşağı ve yukảrı haddi olmayan ve diğer hususlarda para cezalarından ayrulık göstermeyen bir cezadır Bu sebeble Cezayı Azaltıcı Takdirî Sebebin bunlara, hapse çevrilmeleri bahis mevzuu olmayan hallerde de teşmili 59 uncu maddenin mutlak ifadesine daha uygundur:

Cezayı Azaltıcı Sebeblere binaen cezanın indirilmesi, cezaların içtimandan evvel yapılmalıdır. Içtimadan sonra husule gelen cezanin Takdirî Sebeblerle indirilmesi doğru değildir. Çünkü Cezayı Azaltıcı Takdirî Sebeb her suça doğrudan doğruya bağlı bir sebebdir.

59 uncu maddedeki nisbet dahilinde kalmak şartı ile, cezadan yapılacak indirme miktarınin takdirî hükmü veren mahkemeye aittir (24).

(21) Ezcümle Manzini n. 380; Majno 275.

(22) Bu mesele hakkinda bk. Manzini n. 375

(23) CGK 20.12 .943 e. $97 \mathrm{k}$. Ad. derg. 944 ilâve s. 3

(24) Yargitay içtihadı hakkınđa bk. Köseoğlu TCK m. 59. 